\title{
The Effectiveness of Cabbage Leaf Compress and the Education of Lactation Management in Reducing Breast Engorgement in Postpartum
}

\author{
Pipih Napisah ${ }^{1}$, Restuning Widiasih ${ }^{1 *}$ D , Ida Maryati ${ }^{1}$, Yanti Hermayanti ${ }^{1}$, Windy Natasya ${ }^{2}$ \\ ${ }^{1}$ Department of Maternity Nursing, Faculty of Nursing, Universitas Padjadjaran, Bandung, Indonesia; ${ }^{2}$ Departement of Nursing, \\ General Hospital, Hasan Sadikin Hospital, Bandung, Indonesia
}

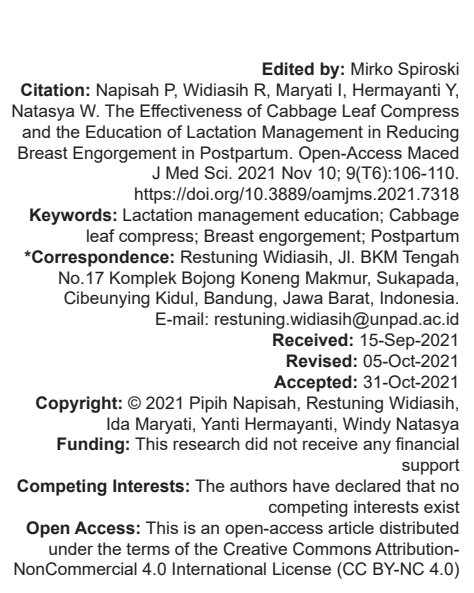

Abstract

BACKGROUND: Breast engorgement is a common problem of breastfeeding. The combination of nursing interventions is expected to prevent and reduce breast engorgement promptly.

AIM: This study aims to determine the effectiveness of cabbage leaf compress and education on lactation management for reducing breast engorgement in postpartum.

METHODS: This study was a quasi-experimental study with a non-equivalent control group design. The sample was 60 postpartum women ( $n=30$ the intervention group and $n=30$ the control group) selected by purposive sampling. The instrument was the Breast Engorgement Scale. The intervention included giving compress on women's breast using the cabbage leaf and educating them about lactation management, while the control group was given treatment according to hospital standard procedures. The study was conducted in a national referral hospital for West Java Province areas, Indonesia. Data were analyzed using the Wilcoxon sign-rank test and the effectiveness of intervention tested using the NGain score test.

RESULTS: There was a difference in breast engorgement scale before intervention with median value \pm min max $(3.00 \pm 2-6)$ and after median $\pm \min \max (2.00 \pm 1-2)$, while in the control group the breast engorgement scale before treatment showed the median was \pm min-max $(2.00 \pm 2-5)$ and after treatment, was $\pm \min -\max (2.00 \pm 1-5)$. The effectiveness of intervention was $77.56 \%$.

CONCLUSIONS: The combination interventions of cabbage leaf compress and lactation management education were effective in reducing the breast engorgement in postpartum. This intervention can be used as an alternative intervention to solve the breast engorgement problem in postpartum women, especially for a developing country like Indonesia, because the cabbage leaf is cheap and easy to get in the traditional market. Further research is expected to conduct research on a qualitative design to understand women's experience after interventions and the possibility to apply this intervention at home.

\section{Introduction}

Breastmilk is the gold standard food for baby recommended by international health organizations and also in Indonesia. However, several conditions such as infants' abnormalities, mothers' health, and pandemic hinder breastfeeding. As a result, mothers do not breastfeed their babies, and would experience breastfeeding problems, such as breast engorgement. The incidence of breast engorgement occurs in almost $90 \%$ of postpartum women [1]. It occurs due to hormonal changes, which is the release of the hormones prolactin and oxytocin would be released, and $24 \mathrm{~h}$ after giving birth the colostrum come out from the breast. Then, the breast becomes full and get heavier (72-96 h), and milk production increases in 3-5 days after the delivery so that the breast will be full with milk, tense, hard, and painful [2]. An appropriate and effective treatment is needed to prevent serious breast problems such as mastitis and breast abscess.
Pharmacological and non-pharmacological interventions to deal with breast engorgement have been widely done, for example, ice compress, cold cabbage leaf compress, ibuprofen, warm water compress, Gua Sha therapy, herbal compress, hollyhock compress, and cabbage compress [2], [3], [4], [5], [6], [7]. These studies have been shown to be effective in reducing engorgement, but some interventions, such as Gua Sha therapy, herbal compress, and hollyhock compress, must be performed by certified health professionals. However, postpartum women with normal labor, especially in Indonesia, need interventions to solve the breast engorgement problem that are easy to do at home by themselves. One of the interventions to reduce breast engorgement that postpartum women can easily do at home is cabbage leaf compress. This intervention does not require special skills is an inexpensive treatment, and has no side effects. One of the interventions to reduce breast engorgement that postpartum women can easily do at home is cabbage leaf compress. This 
intervention does not require special skills, priceless treatment, and no side effects.

The cabbage leaf substances will stimulate the enzyme glutathione in the cytoplasm to decompose the blockages in the milk ducts so that the body reabsorbs the dammed fluid in the breast. In addition, the content of cabbage leaves can reduce local inflammation. Further, these substances stimulate the hypothalamus to activate the effector system for the vasodilation of capillary blood vessels. As a result, there is an increase in blood flow in and out of the clogged area so that it can relieve and eliminate engorgement and breast milk can exit smoothly from the breast [8], [9], [10]. Research on the effectiveness of cabbage leaves for preventing or overcoming breast engorgement has been conducted [11], [12]. The previous studies have been conducted to prevent or decrease breast engorgement in the form of a single intervention and combination intervention. Existing combination interventions are compressing cabbage leaves with cold gel, warm compress, cold compress, and breast massage. None of the study combining an intervention with education about the management of lactation.

Health education is a good strategy to influence other people health behavior. The research of Risadi et al. (2019) found that knowledge about lactation management influences exclusive breastfeeding behavior [13]. Combining two interventions, cabbage leaf compress and health education about lactation management are expected in reducing the breast engorgement. The objective of this study was to determine the effectiveness of cabbage leaf compress and education on lactation management for reducing breast engorgement in postpartum.

\section{Methods}

\section{Study design}

The design of research was quasi-experimental with a non-equivalent control group design. The research processes and protocol were obtained approval from human ethic committee Universitas Padjadjaran number LB.02.01/X.6.5/179/2020.

\section{Sample and settings}

The samples in the study were selected by purposive sampling: 60 postpartum mothers who had physiological breast engorgement. The research sample was divided into two groups. There were 30 respondents in the intervention group and other 30 respondents in the control group. The criteria of samples included postpartum mothers who experience physiological breast engorgement on a scale of 2-6, vital signs are stable, not allergic to cabbage leaves, the results of the cabbage leaf sensitivity test were negative. This study was conducted in a national referral hospital in West Java Province.

\section{Data collection}

The intervention group was 30 people, and the control group was 30 people. The intervention group was given cabbage leaf compression and lactation management education, while the control group was given nursing interventions according to hospital standards (Marmet technique and lactation management education). Compressing is done for $1 \mathrm{~h}$ divided into two sessions and given a 15 min interval.

\section{Data analysis}

The data were analyzed using Wilcoxon signed-rank test for both the intervention group and the control group. The treatment effectiveness was tested using the NGain score test. Before conducting the data analysis test, the researchers conducted a homogeneity test and a normality test. The homogeneity test employed the Levene test, while normality employed the Kolmogorov- Smirnov test.

\section{Research Results}

\section{Level of breast engorgement before and after treatment and lactation management education}

Table 1 shows that most of the respondents were in healthy reproductive age, had high school education, low economy, multiparous, and gave birth with SC surgery.

Table 1: Respondents characteristics from the intervention and the control group

\begin{tabular}{|c|c|c|c|c|}
\hline & \multicolumn{2}{|c|}{ Intervention $(\mathrm{n}=30)$} & \multicolumn{2}{|c|}{ Control $(n=30)$} \\
\hline & $\mathrm{n}$ & $\%$ & $\mathrm{~N}$ & $\%$ \\
\hline \multicolumn{5}{|l|}{ Age } \\
\hline$<19$ & 1 & 3.3 & 1 & 3.3 \\
\hline $20-35$ & 24 & 80 & 26 & 86.7 \\
\hline$>35$ & 5 & 16.7 & 3 & 10 \\
\hline \multicolumn{5}{|l|}{ Education } \\
\hline Elementary school & 1 & 3.3 & 0 & 0 \\
\hline Junior high school & 6 & 20 & 1 & 3.3 \\
\hline Senior high school & 15 & 50 & 21 & 70 \\
\hline $\mathrm{D} 3 / \mathrm{S} 1$ & 8 & 26.7 & 8 & 26.7 \\
\hline \multicolumn{5}{|l|}{ Income } \\
\hline$\geq$ Minimum wage & 17 & 56.7 & 16 & 53.3 \\
\hline$\leq$ Minimum wage & 13 & 43.3 & 14 & 46,7 \\
\hline \multicolumn{5}{|l|}{ Parity } \\
\hline Primipara & 11 & 36.7 & 12 & 40 \\
\hline Multipara & 15 & 50 & 16 & 53.3 \\
\hline Grand multipara & 4 & 13.3 & 4 & 6.7 \\
\hline \multicolumn{5}{|l|}{ Delivery } \\
\hline Normal & 13 & 43.3 & 16 & 53.3 \\
\hline SC & 17 & 56.7 & 14 & 46.7 \\
\hline \multicolumn{5}{|l|}{ Postpartum day } \\
\hline Day 1 & 12 & 40 & 13 & 43.3 \\
\hline Day 2 & 13 & 43.3 & 12 & 40 \\
\hline Day 3 & 3 & 10 & 3 & 10 \\
\hline Day 5 & 2 & 6.7 & 2 & 6.7 \\
\hline
\end{tabular}


Table 2: The breast engorgement levels before and after treatments

\begin{tabular}{|c|c|c|c|c|}
\hline & $\begin{array}{l}\text { Pre } \\
\text { Median + Min-Max }\end{array}$ & $\begin{array}{l}\text { Post } \\
\text { Median + Min-Max }\end{array}$ & $\begin{array}{l}\text { Pre } \\
\text { Median + Min-Max }\end{array}$ & $\begin{array}{l}\text { Post } \\
\text { Median } \pm \text { Min-Max }\end{array}$ \\
\hline \multicolumn{5}{|l|}{ Intervention } \\
\hline Breast engorgement scale (compress cabbage leaves) & $3.00(2-6)$ & $2.00(1-2)$ & $3.00(2-6)$ & $2.00(1-2)$ \\
\hline Breast engorgement scale (education) & $2.00(1-2)$ & $1.00(1-2)$ & $2.00(1-2)$ & $1.00(1-2)$ \\
\hline \multicolumn{5}{|l|}{ Control } \\
\hline $\begin{array}{l}\text { Breast engorgement scale (uncompressed cabbage } \\
\text { leaves) }\end{array}$ & $2.00(2-5)$ & $2.00(1-5)$ & $2.00(2-5)$ & $2.00(1-5)$ \\
\hline Breast engorgement scale (education) & $2.00(1-5)$ & $2.00(2-5)$ & $2.00(1-5)$ & $2.00(2-5)$ \\
\hline
\end{tabular}

Table 2 shows that there was a decrease in the scale of breast engorgement after being given a cabbage leaf compress and education on lactation management in the intervention group compared to the control group.

Table 3 shows that there was an increase in knowledge and attitude scores after being given lactation management education in the intervention group compared to the control group.

Table 3: Scores of knowledge levels and attitudes of lactation management education

\begin{tabular}{|c|c|c|c|c|c|c|c|c|}
\hline & \multicolumn{4}{|c|}{$\begin{array}{l}\text { Intervention } \\
(\mathrm{n}=30)\end{array}$} & \multicolumn{4}{|c|}{$\begin{array}{l}\text { Control } \\
(n=30)\end{array}$} \\
\hline & \multicolumn{2}{|c|}{ Pre } & \multicolumn{2}{|c|}{ Post } & \multicolumn{2}{|c|}{ Pre } & \multicolumn{2}{|c|}{ Post } \\
\hline & $\mathrm{n}$ & $\%$ & $\mathrm{n}$ & $\%$ & $\mathrm{n}$ & $\%$ & $\mathrm{n}$ & $\%$ \\
\hline \multicolumn{9}{|l|}{ Knowledge } \\
\hline Good & 4 & 13.3 & 20 & 66.7 & 6 & 20 & 21 & 70 \\
\hline moderate & 16 & 53.3 & 8 & 26.7 & 22 & 73.3 & 9 & 30 \\
\hline Less & 10 & 33.3 & 2 & 6.7 & 2 & 6.7 & 0 & 0 \\
\hline \multicolumn{9}{|l|}{ Attitude } \\
\hline Supports & 4 & 13.3 & 12 & 40 & 15 & 50 & 25 & 83.3 \\
\hline Not support & 26 & 86.7 & 18 & 60 & 15 & 50 & 5 & 16.7 \\
\hline
\end{tabular}

1. Effect of interventions on decreasing breast engorgement

Table 4 shows that there was a significant difference in breast engorgement scale in the intervention group before and after interventions. The cabbage leaf compress and lactation management education were more effective in reducing breast engorgement in postpartum mothers compared to those without cabbage leaf compress.

Table 4: Effectiveness of lactation management treatment and education in decreasing breast engorgement

\begin{tabular}{llll}
\hline & $\mathrm{Z}$ & $\mathrm{p}$ value & Treatment effectiveness (\%) \\
\hline Intervention & & & \\
Breast engorgement scale (cabbage) & $-4.905^{\mathrm{b}}$ & 0.000 & 77.56 \\
Breast engorgement & $-2.887^{\mathrm{b}}$ & 0.004 & 57.58 \\
scale (education) & & & \\
Control & & & \\
Breast engorgement scale (cabbage) & $-3.066^{\mathrm{b}}$ & 0.002 & 23.89 \\
Breast engorgement & $-1.000^{\circ}$ & 0.317 & - \\
scale (education) & & & \\
\hline
\end{tabular}

\section{Discussion}

\section{Level of breast engorgement before and after treatment}

Based on the result, most of the respondents who experienced breast engorgement, it may be influenced by several factors. This is in accordance with the research by Disha et al. (2015), which found that there is a significant relationship between age and milk production of postpartum mothers who experience breast engorgement between the ages of 25 and 28 years [14]. Witt et al. (2016) found a person's education will affect the learning process [15]. In accordance with research by Abdallah et al. (2018), postpartum mothers who experience breast engorgement experience less monthly income [16]. In reference to the research of Romlah and Sari (2019), there is a relationship between parity and breast milk production [17]. In regard to the research by Lim et al. (2015), breast milk production will increase on the $3^{\text {rd }}$ day postpartum [6]. Thus, many factors can cause breast engorgement in postpartum mothers so that appropriate, effective, inexpensive, and easy interventions are needed by mothers independently at home.

The scale of breast engorgement showed a significant difference before and after being given the cabbage leaf compress and education. These findings are in line with Lowdermilk's theory that cabbage leaf compress can reduce breast engorgement in postpartum mothers [2]. Based on Komalavalli et al. (2019) research, cabbage leaf compress is effective in relieving breast engorgement [18]. This is supported by the research of Astuti and Anggarawati (2018) [19]. However, based on the results of the research by Arora et al. (2009), it was explained that both cabbage leaf compress and hot and cold compress were effective in reducing pain due to breast engorgement [20]. Nevertheless, when comparing the effectiveness, hot and cold compresses are more effective in reducing pain, but respondents in their study preferred cabbage leaf compress because of the low cost and the mother felt more comfortable.

Based on the results of the knowledge and attitude score analysis in the intervention group it shows the score of knowledge before education, which is having good knowledge, as much as $13.3 \%$ in the intervention group and after is $66.7 \%$ and the attitude score before education, namely having a supportive attitude, as much as $13.3 \%$ and after as much as $40 \%$. In the control group, the score of knowledge before education was $20 \%$ good knowledge and $70 \%$ after and the attitude score before education, i.e. having a supportive attitude, as much as $50 \%$ and after as much as $50 \%$. Thus, there was an increase in knowledge and attitude scores after being given lactation management education in the intervention group compared to the control group. This is in accordance with Notoatmodjo 
(2015) who explains that education is a strategy to influence other people, both individuals, groups, and communities so that they do what the education provider expects [21]. Risadi et al. (2019) explain that there is a relationship between knowledge of lactation management and breastfeeding behavior in postpartum mothers [13]. Sari et al. (2017) found a relationship between knowledge about lactation management and breastfeeding attitudes of postpartum mothers, the better the knowledge, the better the mother's attitude in breastfeeding the baby [22]. Lactation management education can increase the knowledge, understanding, and attitudes of mothers in breastfeeding so as to prevent more serious breast engorgement.

\section{The effect of cabbage leaf compress intervention and lactation management education on decreasing breast engorgement}

Based on the results, it showed that there was a significant decrease in the scale of engorgement before and after the cabbage leaf compress. The determination of cabbage leaf compression was based on the research of Wong et al. (2017) that the type of research being carried out was a randomized controlled trial (RCT) [7]. The combination intervention between compressed cabbage leaves and education on lactation management was effective in reducing breast engorgement and decreasing the scale of engorgement. Komalavalli et al. (2019) explained that the cabbage leaf compress was effective in reducing breast engorgement significantly [18], and research by Astuti and Anggarawati (2018) found that there was an effect between compressing cabbage leaves on reducing breast engorgement [19].

The scale of engorgement in the control group decreased before and after treatment. At the same time, the scale of engorgement before and after education, it means that there is no effect. Thus, the intervention in the control group was effective in reducing breast engorgement in postpartum mothers. However, after being given lactation management education, there was no effect, this may be because in the control group most of the postpartum mothers experienced a scale of 2 and mothers with normal deliveries.

In this study, the researcher faced some obstacles. One of them is the COVID-19 outbreak. The researchers had difficulty in exploring patients, actions given to patients should be promptly, health protocol, and transmission prevention standards must be a priority, after conducting interviews with postpartum mothers, they were willing to intervene in overcoming engorgement of the breast. Some respondents were reluctant as they felt embarrassed and they were still more focused on pain after childbirth (taking in period), so the researcher had to find respondents who were willing to be research respondents.

\section{Conclusions}

The combined intervention between cabbage leaf compress and lactation management education was effective in reducing the scale of breast engorgement in postpartum mothers. However, a few barriers were identified related to a deeper exploration of the mother's feelings after the intervention due to the COVID-19 pandemic. Further research is expected to be able to conduct research on a qualitative design to understand women's experience after cabbage leaf compress and education on lactation management, and the possibility to apply this intervention at home by applying both qualitative and quantitative mixed methods.

\section{References}

1. Alekseev NP, Vladimir II, Nadezhda TE. Pathological postpartum breast engorgement: Prediction, prevention, and resolution. Breastfeed Med. 2015;10(4):203-8. https://doi.org/10.1089/ bfm.2014.0047

PMid:25774443

2. Lowdermilk DL, Perry S, Cashion MC. Maternity Nursing. $8^{\text {th }}$ ed. Singapore: Elsevier, Mosby; 2013. https://doi.org/10.1097/ jnr.0b013e3181ce4f8e

3. Chiu JY, Gau ML, Kuo SY, Chang YH, Kuo SC, Tu HC. Effects of gua-sha therapy on breast engorgement: $A$ randomized controlled trial. J Nurs Res. 2010;18(1):1-10.

PMid:20220605

4. Ketsuwan S, Baiya N, Paritakul P, Laosooksathit W, Puapornpong P. Effect of herbal compresses for maternal breast engorgement at postpartum: A randomized controlled trial. Breastfeed Med. 2018;13(5):361-5. https://doi.org/10.1089/bfm.2018.0032 PMid:29688768

5. Khosravan S, Moghadam HM, Mohammadzadeh F, Fadafen SA, Gholami M. The effect of Hollyhock (Althaea officinalis L) leaf compresses combined with warm and cold compress on breast engorgement in lactating women: A randomized clinical trial. J Evid Based Complement Altern Med. 2017;22(1):25-30. https://doi.org/10.1177/2156587215617106

PMid:26603219

6. Lim AR, Song JA, Hur MH, Lee MK, Lee MS. Cabbage compression early breast care on breast engorgement in primiparous women after cesarean birth: A controlled clinical trial. Int J Clin Exp Med. 2015;8(11):21335-42

PMid:26885074

7. Wong BB, Chan YH, Leow MQ, Lu Y, Chong YS, Koh SS, et al. Application of cabbage leaves compared to gel packs for mothers with breast engorgement: Randomised controlled trial. Int J Nurs Stud. 2017;76:92-9. https://doi.org/10.1016/j. ijnurstu.2017.08.014 PMid:28941842

8. Zuhana N. The difference in the effectiveness of cold cabbage leaves (Brassica Oleracea Var. Capitata) w. J Ilm Bidan. 2017;2(2):51-6. https://doi.org/10.35906/vom.v10i2.119

9. Wijayanti AA, Widyastutik D. The effectiveness of cabbage lea (Brassica oleracea Var Capitata) compresses management and breast care on brea. JBI Libr Syst Rev. 2018;2(4):238-43. https://doi.org/10.35906/vom.v10i2.119 
10. Pustaka Agung Harapan. Amazing herbal medicine? Surabaya: Pustaka Agung Harapan; 2011.

11. Deswani D, Gustina G, Rochimah R. The placebo effect of cabbage leaf compresses in dealing with breast engorgement in postpartum women. Open Access Maced J Med Sci. 2014;2(3):13-23.

12. Roberts K, Reiter M, Schuster D. Effect of cabbage leaf extract on breast engorgement. J Hum Lact. 1998;14(3):231-6. https:// doi.org/10.1177/089033449801400312

PMid:10205435

13. Risadi CA, Mashabi NA, Nugraheni PL. The effect of mother's knowledge about lactation management on exclusive breastfeeding behavior. J Kesejaht Kel Pendidik. 2019;6(1):2532. https://doi.org/10.21009/jkkp.061.04

14. Disha D, Rana A, Singh A, Suri V. Effect of chilled cabbage leaves vs. Hot compression on breast engorgement among post natal mothers admitted in a tertiary care hospital. Nurs Midwifery Res Res. 2015;11(1):24-32. https://doi.org/10.33698/ nrf0181

15. Witt AM, Bolman M, Kredit S. Mothers value and utilize early outpatient education on breast massage and hand expression in their self-management of engorgement. Breastfeed. Med. 2016;11(9):433-9. https://doi.org/10.1089/bfm.2016.0100
16. Abdallah NM, Eldin SA, Gad AH. Breast and nipple problems encountered among puerperal primipara women in Zagazig. Int J Pharm Res Allied Sci. 2018;7(1):183-95.

17. Romlah R, Sari AP. Risk factors in breastfeeding and breastmilk production at the 23 llir Public Health Center in Palembang. J Kesehat Poltekkes Palembang. 2019;14(1):32-7. https://doi. org/10.36086/jpp.v14i1.285

18. Komalavalli K, Narmada N, Mohana M. Effectiveness of cabbage leaves application on breast engorgement among postnatal mothers at Karpaga Vinayaga Institute of Medical Sciences and Reserch, Masuranthagam Taluk in Kancheepuram District. Global J Res Anal. 2019;6:115-7.

19. Astuti $Y$, Anggarawati $T$. The effect of cabbage compresses on breast engorgement of postpartum sectio caesarea ibu. Indones J Nurs Res. 2018;2(1):93. https://doi.org/10.34310/jskp.v4i1.93

20. Arora S, Vatsa M, Dadhwal V. A comparison of cabbage leaves vs. hot and cold compresses in the treatment of breast engorgement. Indian J Community Med 2009;33(3):160. https:// doi.org/10.4103/0970-0218.42053

21. Notoatmodjo N. Health Research Methods. Jakarta: Rineka Cipta; 2015.

22. Sari T, Mudayati S, Lasri L. Knowledge of lactation management and attitudes of postpartum mothers in the breastfeeding process. Int J Health Sci 2017;3(2):45-54. 